\title{
Immunological and Nonimmunological Effects of Indoleamine 2,3-Dioxygenase on Breast Tumor Growth and Spontaneous Metastasis Formation
}

\author{
Vera Levina, ${ }^{1,2,3}$ Yunyun Su, ${ }^{1}$ and Elieser Gorelik ${ }^{1,2,4}$ \\ ${ }^{1}$ Department of Medicine, University of Pittsburgh Cancer Institute, Pittsburgh, PA 15213, USA \\ ${ }^{2}$ University of Pittsburgh Cancer Institute, Hillman Cancer Center, Pittsburgh, PA 15213, USA \\ ${ }^{3}$ Department of Immunology, University of Pittsburgh Cancer Institute, Pittsburgh, PA 15213, USA \\ ${ }^{4}$ Department of Pathology, University of Pittsburgh Cancer Institute, Pittsburgh, PA 15213, USA \\ Correspondence should be addressed to Vera Levina, levinav@upmc.edu \\ Received 27 January 2012; Accepted 6 March 2012 \\ Academic Editor: Masoud H. Manjili
}

Copyright ( $) 2012$ Vera Levina et al. This is an open access article distributed under the Creative Commons Attribution License, which permits unrestricted use, distribution, and reproduction in any medium, provided the original work is properly cited.

\begin{abstract}
The role of the tryptophan-catabolizing enzyme, indoleamine 2,3-dioxygenase (IDO1), in tumor escape and metastasis formation was analyzed using two pairs of Ido1+ and Ido1- murine breast cancer cell lines. Ido1 expression in $4 \mathrm{~T} 1$ cells was knocked down by shRNA, and Ido1 expression in NT-5 cells was upregulated by stable transfection. Growth of Ido1- tumors and spontaneous metastasis formation were inhibited in immunocompetent mice. A higher level of cytotoxic T lymphocytes was generated by spleen cells from mice bearing Ido1 - tumors than Ido1+ tumors. Tumor and metastatic growth was enhanced in immunodeficient mice, confirming an intensified immune response in the absence of Ido1 expression. However, Ido1+ tumors grow faster than Ido1tumors in immunodeficient SCID/beige mice (lacking T, B, and NK cells) suggesting that some Ido1-controlled nonimmunological mechanisms may be involved in tumor cell growth regulation. In vitro experiments demonstrated that downregulation of Ido1 in tumor cells was associated with decreased cell proliferation, increased apoptosis, and changed expression of cell cycle regulatory genes, whereas upregulation of Ido1 in the cells had the opposite effects. Taken together, our findings indicate that Ido1 expression could exert immunological and nonimmunological effects in murine breast tumor cells.
\end{abstract}

\section{Introduction}

Immune escape is one of the hallmarks of cancer [1]. There are a variety of active mechanisms of immune suppression that are elaborated by tumors to drive immune escape, such as the loss of MHC class I molecules or tumor antigens, induction of T regulatory cells, and the production of various immunosuppressive molecules (IL-10, TGF- $\beta$, adenosine, PGE2, etc.) [2-4]. One mechanism of immune escape that has been linked to cancer is elevation of the tryptophancatabolizing enzyme, indoleamine 2,3-dioxygenase (IDO1) [5-14].

IDO1 can be expressed in many tissue and cell types, such as placenta, lung, gut, and epididymis [13, 15-17]. The expression of IDO1 at the maternal-fetal interface in mice placenta is believed to play a role in the protection of the fetus from immunologic rejection by maternal immune mechanisms [18]. Indeed, this has been supported experimentally wherein the pharmacological inhibition of IDO1 by 1-methyltryptophan (1MT) resulted in the rejection of allogeneic, but not syngeneic, murine fetuses [19-21]. Ido1 activation occurs commonly in tumor cells and/or tumordraining lymph nodes (TDLNs), and pharmacological inhibition of IDO1 with 1-MT has been shown to result in T-celldependent antitumor responses in animal models $[8,22-$ 27]. 1-MT was observed to retard tumor outgrowth but was unable to trigger complete tumor regression [6]. In vitro studies indicate that IDO1 is capable of exerting suppressive effects directly on $\mathrm{T}$ cells and can activate suppressive populations of regulatory $\mathrm{T}$ cells $[8,9]$. Furthermore, soluble cytotoxic-T-lymphocyte-antigen-4- (CTLA4-) expressing T regulatory cells induce IDO1 expression in DC, converting them into regulatory antigen-presenting cells (APCs) $[24,26]$. Intracellular signaling via CD80/86, CD200R, and FceRI 
could induce IDO1 expression by DC $[9,13,25]$. A tumorrelated immune escape mechanism based on tryptophan degradation by IDO1 has been proposed $[22,28]$. Ido1 is expressed by tumor cells; however, the level of Ido1 expression is significantly lower than in placenta. Tumor cell inhibition of immune response was only demonstrated for Ido1-transfected clones, exhibiting 1000-fold increased expression of Ido1 mRNA relative to placental levels [22, 29]. Thus, a role for IDO1 in tumor immune response is indicated but requires further investigation.

In this study, we examined the impact of IDO1 on tumor growth and metastasis in immune-competent and immunedeficient mice. Two murine breast cell lines, 4T1 and NT5, expressing Ido1 and missing Ido1 expression, respectively, were utilized. NT-5 cells were transfected with an Ido1 expression vector to establish an NT-5/Ido1+ line. Expression of Ido1 in 4T1 cells was knocked down by transfection with an Ido1- specific shRNA expressing plasmid to establish a 4T1/Ido1- line. Using these two pairs of cell lines, we examined the relationship between Ido 1 expression and cancer cell growth in vitro and in vivo. Our analysis of tumor growth and metastasis, in immunocompetent and immunodeficient mice, revealed that IDO1 not only modulated the immunological system, but also played an important biological role in tumor cell proliferation, cell cycle regulation, and antiapoptotic signaling.

\section{Materials and Methods}

2.1. Tumor Cell Lines. The NT-5 HER-2/neu-expressing tumor cell line was provided by Elizabeth Jaffe, John Hopkins University. The 4T1 mouse mammary tumor cell line was purchased from American Type Culture Collection. Cells were cultured in RPMI-1640 medium (Cellgro Mediatech, Inc, Manassas, VA) supplemented with 10\% FBS (SigmaAldrich Co, St. Luis, MO).

2.2. Plasmid Construction and Cell Transfection. The mammalian expression vector for Ido1 was constructed by inserting full-size mouse Ido1 cDNA into the vector $\mathrm{pRc} / \mathrm{CMV}$ (Invitrogen, Life Technologies Corp., Carlsbad, CA). NT5 cells were cloned, and IDO expression in the individual clones was evaluated. The clone with the lowest IDO1 expression was used for transfection with either Ido1 constructs or control pRc/CMV vector using Lipofectamine 2000 according to manufacturer instructions (Invitrogen). Stable transfectants (NT-5/Ido1+ and NT-5/vector) were selected by growth in a medium supplemented with $400 \mu \mathrm{g} / \mathrm{mL}$ G418 (Sigma-Aldrich Co). IDO-positive 4T1 breast tumor cells were also cloned, and the clone with highest IDO expression was transfected with shRNA against IDO containing plasmid and the control plasmid (SABiosences). Stably transfected $4 \mathrm{~T} 1 / I d o 1-$ and $4 \mathrm{~T} 1 /$ vector cells were selected with $600 \mu \mathrm{g} / \mathrm{mL}$ of G418 (Sigma-Aldrich).

2.3. Real-Time PCR and Gene Expression Profiling. RNA was isolated from the cells using the RNeasy kit from Qiagen (Valencia, CA), and the extracted RNA was converted to cDNA using the $\mathrm{RT}^{2}$ First Strand Kit from Super Array Bioscience Corporation (Frederick, MD) according to manufacturer's protocols. Real-time PCR was carried out using the Super Array RT ${ }^{2}$ Real-Time SYBR Green PCR Master Mix (Super Array Bioscience) and was performed on the ABI Prism 7700 sequence detector real-time PCR system (AB Applied Biosystems, Foster City, CA). Primers for mouse IdoI were forward $5^{\prime}$-GTACATCACCATGGCGTATG-3'; reverse: $5^{\prime}$-CGAGGAAGAAGCCCTTGTC-3'. Standard curves were generated from five 10-fold serial dilutions of tumor cell CDNA, and no product could be observed in the negative control lacking template. Differences in gene expression were calculated by using the $\triangle \mathrm{Ct}$ method and normalized to GAPDH according to the manual from Super Array Bioscience (Super Array, Bioscience Corp., Frederick, MD).

The RT ${ }^{2}$ Profiler PCR Array System and mouse cell cycle regulation $\mathrm{RT}^{2}$ Profiler PCR Array (Super Array, Bioscience Corp) were used. Real-time PCR detection was carried out per the manufacturer's instructions. The experimental cocktail was prepared by mixing cDNA isolated from cell lines with the RT ${ }^{2}$ Real-Time SyBR Green/ROX qPCR Master Mix (SABiosciences Corp., Frederick, MD). The mixtures were equally aliquoted into the 96 -well plate containing predispensed gene-specific primer sets, then real-time PCR was performed using the ABI Prism 7900HT (ABI, Applied Biosytems Corp., Foster City, CA). Differences in genes expression were compared between $4 \mathrm{~T} 1 /$ vector and $4 \mathrm{~T} 1 /$ Ido1cells or between NT-5/vector and NT-5/Ido1+ cells. Analyses of the raw data were done through the Super Array Data Analysis Web Portal (Super Array Bioscience Corp.).

2.4. Enzymatic Assay for IDO Activity. IDO activity was determined using what is described in $[10,30]$. Briefly, cell extracts were prepared, mixed with an equal volume of $2 \mathrm{x}$ reaction buffer $(100 \mathrm{mM}$ PBS, $40 \mathrm{mM}$ ascorbate, $20 \mu \mathrm{M}$ methylene blue, $200 \mu \mathrm{g} / \mathrm{mL}$ catalase, $800 \mu \mathrm{M}$ L-Tryptophan (Affymetrix, USB Inc, Cleveland, OH), pH 6.5), and incubated at $37^{\circ} \mathrm{C}$ for $30 \mathrm{~min}$ in order to permit IDO-mediated conversion of L-Trp into N-formylkynurenine. The reaction was stopped with $30 \%$ trichloroacetic acid, and samples were incubated at $50^{\circ} \mathrm{C}$ for $30 \mathrm{~min}$ to hydrolyze the $\mathrm{N}$ formylkynurenine produced to kynurenine. After centrifugation, supernatants were collected and mixed with Ehrlich's reagent $(0.8 \% \mathrm{p}$-dimethylaminobenzaldehyde in acetic acid) in 96-well plates, and absorbance at $490 \mathrm{~nm}$ was measured on a microplate reader. IDO activity is defined as the amount of enzyme required to produce $1 \mathrm{nmol}$ of kynurenine per hr per $\mathrm{mg}$ of protein.

2.5. In Vitro Cell Proliferation Assay. The cells were cultured in a 96-well plate for 2 days and pulsed with $0.2 \mu \mathrm{Ci} /$ well of ${ }^{3} \mathrm{H}$-thymidine overnight followed by collection of supernatant. $50 \mathrm{uL}$ of supernatant was mixed with $2 \mathrm{~mL}$ of CytoSpin (MP, Biomedicals LLC, Solon, OH) and counted by liquid scintillation counter (Wallac). The tumor cells were also counted by Cellomics Array Scan HCS Reader (Thermo Fisher, Pittsburgh, PA) following 3 days in culture as described previously [31]. 
2.6. Flow Cytometry Analysis. Cells were cultured in a control medium or in serum starvation conditions (RPMI with $0.1 \%$ FBS or $0.3 \%$ FBS) for 3 days followed by culture in RPMI with $10.0 \%$ FBS for 24 hours. Cells were stained with FITCconjugated antibromodeoxyuridine (BrdU) and/or propidium iodide (PI) using FITC BrdU Flow Kit (BD Biosciences, Pharmingen, San Diego, CA) according to the manufacturer's instruction. Flow cytometry was performed by CYAN ADP (Beckman Counter, Brea, CA). The data were analyzed with the Cytomation Summit v4.3 software.

2.7. In Vivo Local and Metastatic Tumors Assays. BALB/c, $\mathrm{FVB} / \mathrm{N}$, and SCID-beige were purchased from The Jackson Laboratory (Bar Harbor, ME) and used at 8-9 weeks of age. Mice were housed in the University of Pittsburgh Cancer Institute animal facility which is accredited for animal care by the American Association of Laboratory Animal Care. Experiments were performed in accordance with the approved institutional protocol and the guidelines of the Institutional Animal Care and Use Committee. BALB/c and SCID-beige mice were inoculated s.c. with $2.5 \times 10^{4}$ or $1.0 \times 10^{5}$ of $4 \mathrm{~T} 1 /$ vector cells or $4 \mathrm{~T} 1 / \mathrm{Ido} 1$ - cells per mouse; FBV/N and SCID-beige mice were inoculated s.c. with $5 \times 10^{6}$ of NT-5 or NT-5/Ido1+ cells per mouse. Tumor growth was evaluated by measurement of tumor diameters 3 times a week, and the tumor volume was calculated as length $\times$ width $^{2} \times 0.52$. All data is represented as mean \pm SE. Experiments were terminated when tumors reached $2.0 \mathrm{~cm}$ in diameter. Each group contained 10 mice. Experiments were repeated twice. Lungs were harvested when tumors reached approximately $2 \mathrm{~cm}$ in diameter and fixed in Bounce solution. Metastases were counted under a dissecting microscope.

2.8. Cytotoxicity Assay. Spleen cells from BALB/c mice bearing $4 \mathrm{~T} 1 /$ Ido $1-$ or $4 \mathrm{~T} 1$ tumors were cultured with irradiated (15,000 rad) $4 \mathrm{~T} 1 /$ Ido1- or $4 \mathrm{~T} 1$ tumor cells for 5-8 days in the presence of $300 \mathrm{IU} / \mathrm{mL}$ of IL-2 in 24 -well plates at the ratio as $3 \times 10^{6}$ spleen cells: $1 \times 10^{6}$ tumor cells. The cytotoxic activity of restimulated spleen cells was tested against ${ }^{51} \mathrm{Cr}$-labeled $4 \mathrm{~T} 1 / \mathrm{Ido1}-$ or $4 \mathrm{~T} 1$ cells at the effector: target ratio as $100: 1$. Spleen cells were distributed into V-96well plates preloaded with ${ }^{51} \mathrm{Cr}$-labeled tumor cells; 96-well plates containing cell mixtures were centrifuged at $2000 \mathrm{rpm}$ for 2 minutes and then incubated 4 hours at $37^{\circ} \mathrm{C} .25 \mu \mathrm{L}$ of supernatant was transferred into yttrium silicate scintillatorcoated microplates (LumaPlate-96, PerkinElmer) and left overnight at RT. The level of $\beta$-emission released by ${ }^{51} \mathrm{Cr}$ was measured in a $\beta$-counter.

2.9. Western Blot Analysis. The cells were lysed in RIPA buffer supplemented with 1\% CLAP cocktail (antipan, leupeptin, pepstatin, and chymostatin) and $1 \mathrm{mM}$ PMSF. $50 \mathrm{ug}$ of protein extracts were resolved on $4.5-12 \%$ of SDS-PAGE and transferred to PVDF membranes (Bio-Rad, Hercules, CA). The membranes were blocked with 5\% nonfat dry milk in TBST buffer, probed with antibodies against stratifin (1:200, Sigma), and Atm ( $1: 200$, Santa Cruz Biotechnology, Inc, Santa Cruz, CA) for two hours at RT or overnight at $4^{\circ} \mathrm{C}$, and then incubated with horseradish peroxidase-labeled secondary antibody (Santa Cruz). The signals were detected by ECL (Amersham). Films were scanned and analyzed by Image-QuanT data analysis software (Molecular Dynamics).

2.10. Statistical Analysis. Data are presented as mean $\pm \mathrm{SD}$. Comparisons between values were performed using a twotailed Student's $t$-test. For the comparison of multiple groups, a one- or two-way ANOVA test was applied. For all statistical analyses, the level of significance was set at a pro bability of $P<0.05$. All experiments were repeated 2-3 times.

\section{Results}

3.1. Establishment of Two-Paired Stable Clones (Ido1- and Ido1+) of Murine Breast Cancer Cells. Initially, we measured Ido1 expression in a panel of mouse tumor cell lines of differing histological origin. Two mouse breast tumor cell lines, 4T1 and NT-5, which showed differential expression of Ido1, were chosen. 4T1 cells, derived from sporadic breast tumor in BALB/c mice, are highly aggressive, metastatic, and poorly immunogenic $[32,33]$. NT-5 breast tumor cells are derived from HER-2/neu-transgenic FBV/N mice, and they are immunogenic [34].

We found that $4 \mathrm{~T} 1$ cells express Ido1, whereas the level of Ido1 gene expression in NT-5 cells was very low (Ido1-). Clonal variation could be attributable whenever transfection is performed on a polyclonal whole cell population. To avoid this, our transfections were designed as follows: 4T1 breast tumor cells were cloned using a standard approach for selecting single-cell clones. Ido1 expression, in these individual cell clones, was evaluated. The clone the of the 4T1 tumor cells with the highest Ido1 expression was transfected with IdoI siRNA and a control vector to generate stable 4T1/Ido1- and $4 \mathrm{~T} 1 /$ vector clones.

Similarly, NT-5 cells (expressing Ido1 at a very low level) were also cloned, and the clone of NT- 5 cells, with the lowest level of Ido1 expression, was selected for transfection with cDNA encoding Ido1 or control plasmid.

As shown in Figure 1(a), very low Ido1 expression was detected by RT-PCR in 4T1/Ido1 - cells compared with $4 \mathrm{~T} 1$ and 4T1/vector cells. The quantitative RT-PCR analysis revealed $78 \%$ downregulation of Ido1 in 4T1/Ido1- cells, and no changes of Ido1 expression in 4T1/vector cells in comparison with naïve 4T1 cells (Figure 1(a)).

IFN- $\gamma$ is a known inducer of Ido1 [30]. We tested whether Ido1 expression could be induced by IFN- $\gamma$ in 4T1, 4T1/ vector, and 4T1/Ido1 - cells. Ido1 expression was strongly increased (30-fold change) in 4T1, and 4T1/vector cells were treated with IFN- $\gamma$ (Figure 1(b)). However, Ido1 activation was abrogated in shRNA-transfected cells (4T1/Ido1-) (Figure 1(b)).

We transfected an Ido1 vector and scramble vector into the Ido1 low-expressing NT-5 cells and established stable Ido1 expressing NT-5/Ido1+ and NT-5/vector clones. RTPCR analysis showed Ido1 expression in NT-5/Ido1+ cells, and very low expression in NT-5/vector cells (Figure 1(c) top); quantitative RT-PCR demonstrated a 50.9-fold increase 


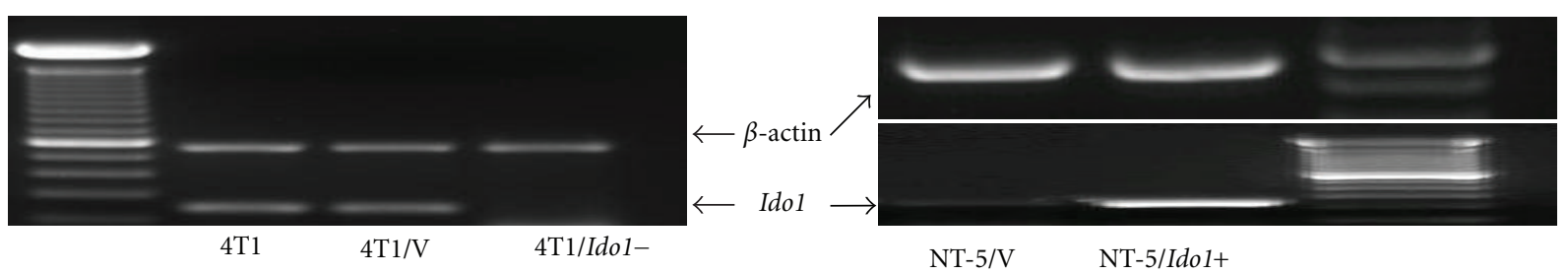

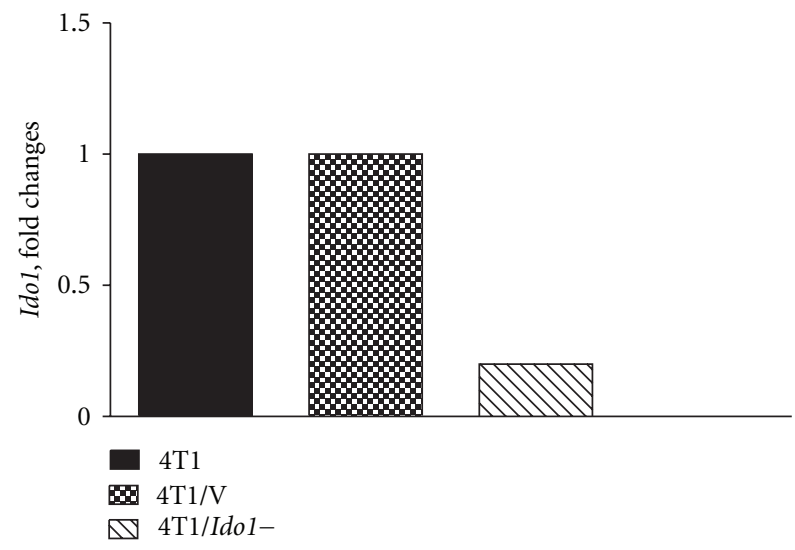

(a)

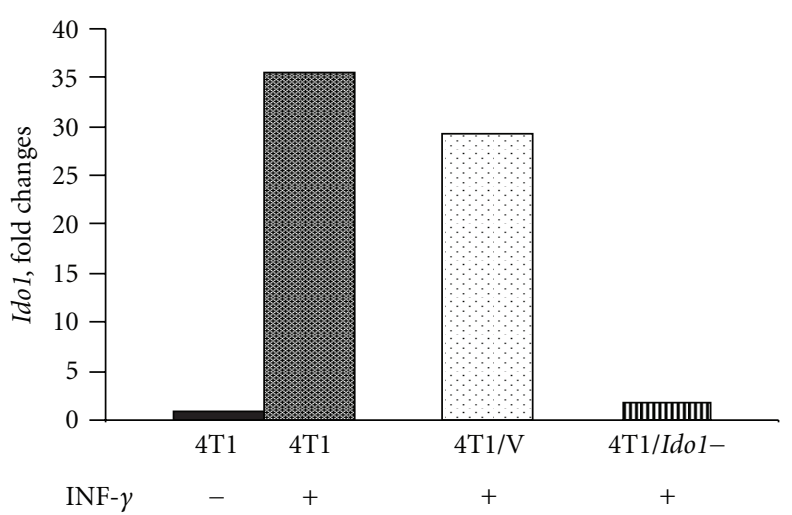

(b)

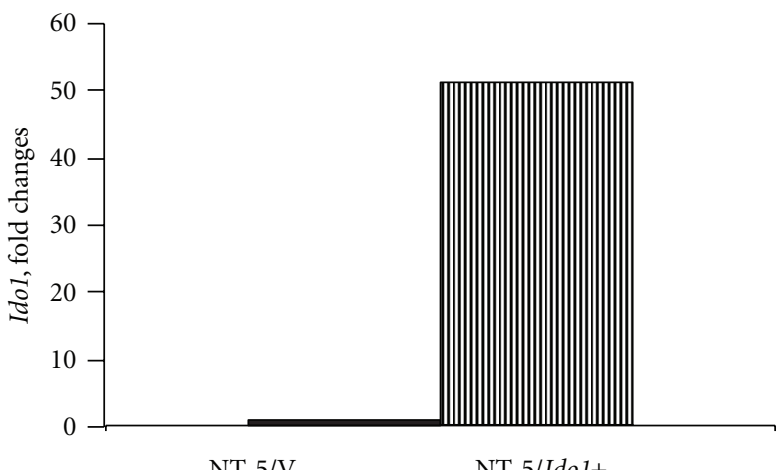

NT-5/V (c)

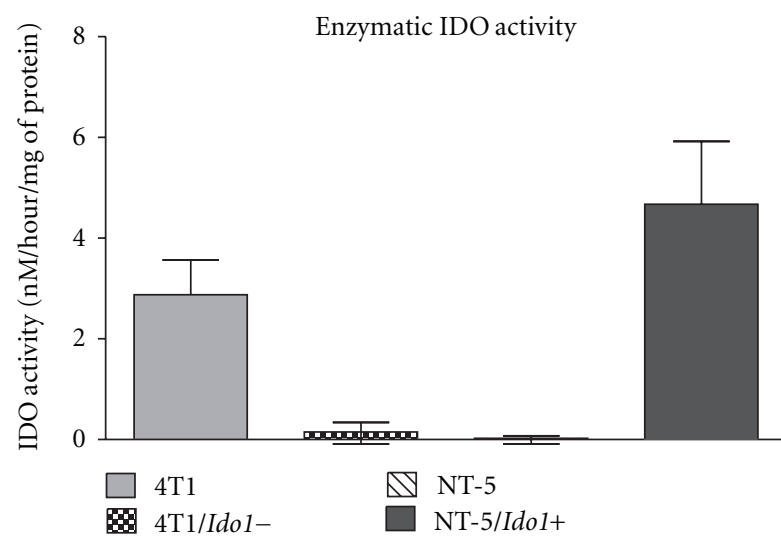

(d)

FIGURE 1: Generation of two pairs of Ido1+ and Ido1- clones from murine breast cancer cells. (a) RT-PCR (top picture) real-time PCR (bottom picture) analysis of Ido1 expression in $4 \mathrm{~T} 1$ cells, cells transfected with vector $(4 \mathrm{~T} 1 / \mathrm{V})$, and cells transfected with shRNA for Ido1 (4T1/Ido1-). Fold change was compared with 4T1. (b) Real-time PCR analysis of the effect of INF- $\gamma$ treatment (INF- $\gamma$, $25 \mathrm{ng} / \mathrm{mL}, 24$ hours) on Ido1 expression in 4T1, 4T1/V, and 4T1/Ido1 - cells. (c) Ido1 expression in NT-5 cells transfected with vector (NT-5/V) and cells transfected with Ido1 cDNA (NT-5/Ido1+) detected by RT-PCR (top picture) and by Real-time PCR (bottom picture). (d) Enzymatic IDO activity in 4T1, 4T1/Ido1-, NT-5, and NT-5/Ido1+ cells. IDO activity is defined as the amount of enzyme required to produce 1 nmol of kynurenine per hr per $1 \mathrm{mg}$ of protein. All values are the means of four measurements.

of Ido1 expression in NT-5/Ido1+ cells in comparison to NT$5 /$ vector cells (Figure 1(c)).

Next, we tested enzymatic activity of IDO in $4 \mathrm{~T} 1,4 \mathrm{~T} 1 /$ Ido1- NT-5, and NT-5/Ido1+ cells (Figure 1(d)). 4T1/Ido1cells demonstrated a significant reduction of IDO activity in comparison with $4 \mathrm{~T} 1$ cells, while NT-5/Ido1+ cells showed a significant increase in IDO activity when compared with NT- 5 cells (Figure $1(\mathrm{~d})$ ).
3.2. Effect of Ido1 Expression on Tumor Growth and Metastasis Formation. To determine the role of IDO1 in tumor growth, BALB/c mice were inoculated s.c. with $4 \mathrm{~T} 1 /$ vector or 4T1/Ido1 - tumor cells. 4T1/Ido1 - tumors grew significantly $(P<0.05)$ slower than $4 \mathrm{~T} 1 /$ vector tumors (Figure $2(\mathrm{a}))$. Mice bearing $2 \mathrm{~cm}$ tumors were sacrificed according to our IACUC-approved protocol, and surviving mice bearing tumors of less than $2 \mathrm{~cm}$ were counted at sequential time 
TABLE 1: Spontaneous lung metastases formation by 4T1/Ido1+, 4T1/Ido1- or NT-5/Ido1+, NT-5/Ido1- tumors in immunocompetent and immunodeficient mice.

\begin{tabular}{lcc}
\hline Mice $^{1}$ & \multicolumn{2}{c}{ No. of spontaneous pulmonary metastases } \\
& 4T1/Ido1+ tumors & 4T1/Ido1- tumors \\
\hline BALB/c & $56 ;(41,51,56,66,182)$ & $21 ;(6,12,21,24,29)^{*}$ \\
SCID-beige & $54 ;(23,24,54,75,164)$ & NT-5/Ido1- tumors \\
\hline Mice $^{1}$ & NT-5/Ido1+ tumors & $1.5 ;(0,0,0,0,3,4,8,10)^{*}$ \\
\hline FVB/N & $6 ;(0,2,3,5,6,7,8,11,14)$ & $13 ;(0,3,12,13,13,13,14,15)$ \\
SCID-beige & $25 ;(11,12,16,24,25,26,28,32,44)^{*}$ & \\
\hline
\end{tabular}

${ }^{1} \mathrm{BALB} / \mathrm{c}$ and SCID-beige were inoculated s.c. with $2.5 \times 10^{4} 4 \mathrm{~T} 1 / \mathrm{Ido1}+$ or $4 \mathrm{~T} 1 /$ Ido1- tumor cells. FVB/N and SCID-beige were inoculated s.c. with $5 \times 10^{6}$ NT-5/Ido1+ or NT-5/Ido1 - tumor cells. When tumors reached about $2 \mathrm{~cm}$ in diameter, lungs were harvested and fixed in the Bounce solution. Metastases were counted under dissecting microscope. * Significantly $(P<0.05)$ differ from all other groups.

points in order to evaluate survival. At the time of complete mortality in the control group, we observed nearly $50 \%$ survival of mice bearing Ido1 - tumors (Figure 2(b)).

The elevated survival of mice bearing 4T1/Ido1- tumors may be a result of a less efficient immune response against tumor cells demonstrating inhibited Idol expression. To assess the immune response of $\mathrm{BALB} / \mathrm{c}$ mice to $4 \mathrm{~T} 1 /$ vector and $4 \mathrm{~T} 1 /$ Ido1 - tumors, spleens of mice bearing tumors were harvested, and spleen cell suspensions were prepared. Freshly prepared spleen cells had no cytotoxic activity against 4T1 tumor cells. Therefore, spleen cells were stimulated with irradiated 4T1 tumor cells for 5-8 days in the presence of IL-2 $(300 \mathrm{IU} / \mathrm{mL})$. We observed no difference in the abilities of irradiated 4T1/Ido1- and 4T1 (Ido1+) cells to stimulate spleen cells and generate cytotoxic $\mathrm{T}$ cells. The cytotoxic activity of stimulated spleen cells appeared after 5 days of stimulation and became more prominent after 7-8 days. Spleen cells obtained from irradiated 4T1/Ido1 tumor cells from 4T1/Ido1- tumor bearing mice demonstrated a higher cytotoxic activity than spleen cells from mice bearing $4 \mathrm{~T} 1 /$ vector tumors (Figure 2(c)). Furthermore, targeted 4T1/Ido1 - tumor cells were more sensitive to the cytotoxic activity of spleen cells than 4T1/vector cells (Figure 2(c)). Spleen cells cultured in IL-2 (300 IU/mL) without irradiated tumor cells showed no cytotoxic activity (data no shown). These results indicate that inhibition of 4T1/Ido1 - tumor growth in BALB/c mice could be due to an elevated immune response against these cells as well as a greater sensitivity of 4T1/Ido1- cells to immune destruction.

To further test whether 4T1/Ido1- tumor growth inhibition is immunologically mediated, immunocompetent $\mathrm{BALB} / \mathrm{c}$ mice or immunodeficient SCID-beige mice (which lack T, B, and NK cells) were inoculated s.c. with $4 \mathrm{~T} 1 /$ vector and 4T1/Ido1- cells. Our expectation was that if differences in Ido1+ and Ido1- tumor growth are immune modulated, then both tumors should grow similarly in SCID/beige mice. Tumor growth from Ido1 - cells was inhibited in comparison with Ido1+ cells in BALB/c mice. As shown in Figure 2(d), both Ido1- and Ido1+ tumors grew faster in immunodeficient SCID/beige mice than in immunocompetent BALB/c mice. However, Ido1+ tumors grew faster than Ido1- tumors in SCID/beige mice suggesting that some Ido1-controlled nonimmunological mechanisms may be involved in tumor cell growth regulation.
To test whether spontaneous pulmonary metastasis formation is dependent on Ido1 gene expression, the number of metastases in BALB/c and SCID/beige mice was counted when tumors reached $2 \mathrm{~cm}$ in diameter. We found that $4 \mathrm{~T} 1 /$ Ido1 - cells generated significantly less metastasis in the lungs of BALB/c mice than $4 \mathrm{~T} 1$ cells (92 versus 396) (Table 1). The pulmonary metastases observed in immunodeficient SCIDbeige mice bearing Ido1- tumors were higher than in the immunocompetent BALB/C mice bearing Ido1- tumors (Table 1).

To further elucidate the role of IDO1, in tumor growth and metastasis formation, we used NT-5/Ido1 - cells and NT5/Ido1+ tumor cells and FVB/N mice that are immunocompetent for NT-5 cells. It is known that NT- 5 breast tumor cells, derived from HER-2/neu-transgenic FBV/N mice, are immunogenic [34]. Indeed, tumor growth was prevented when $1 \times 10^{6} \mathrm{NT}-5$ cells were inoculated into mice. However, inoculation of $5 \times 10^{6}$ NT- 5 cells resulted in tumor development. Tumor growth in many FVB/N mice was associated with enormous necrosis which made it difficult to measure tumor size; therefore, mice were sacrificed when they showed signs of moribund, and lung metastases were counted. We found that NT-5/Ido1+ cells are more metastatic than NT5/Ido-cells in immunocompetent FVB/N mice (Table 1). The numbers of metastases developed from NT-5/Ido1+ cells and NT-5/Ido - cells in immunodeficient SCID/beige mice were significantly higher than in $\mathrm{FVB} /$ mice (Table 1 ). However, even in immunodeficient mice, NT-5/Ido1- cells developed less metastasis than NT-5/Ido1+ cells.

Taken together, these results indicate that $I d o 1$ plays role in tumor growth and metastasis formation.

\subsection{Effect of Ido1 Expression on Apoptosis Changes Cell Cycle} and Tumor Cell Proliferation In Vitro. The differences in Ido1+ and Ido1- tumor growth in immunodeficient mice indicate a possible role of Ido1 in apoptosis and tumor cell proliferation. To analyze cell cycle distribution, in Ido1+ and Ido1- cells, we used flow cytometry and FITC-conjugated antibromodeoxyuridine (BrdU) and/or propidium iodide (PI) staining. The approach relies on the detection of $5^{\prime}-$ bromo-2' -deoxyuridine (BrdU) incorporation which identifies DNA-replicating cells, and PI staining reveals the distribution of cells in three major phases of the cycle (G1 ver- 


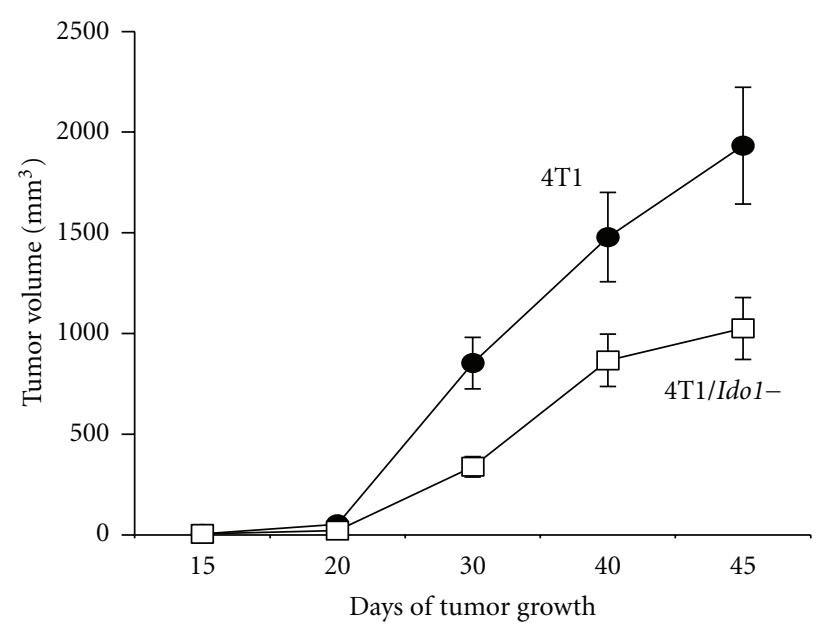

(a)

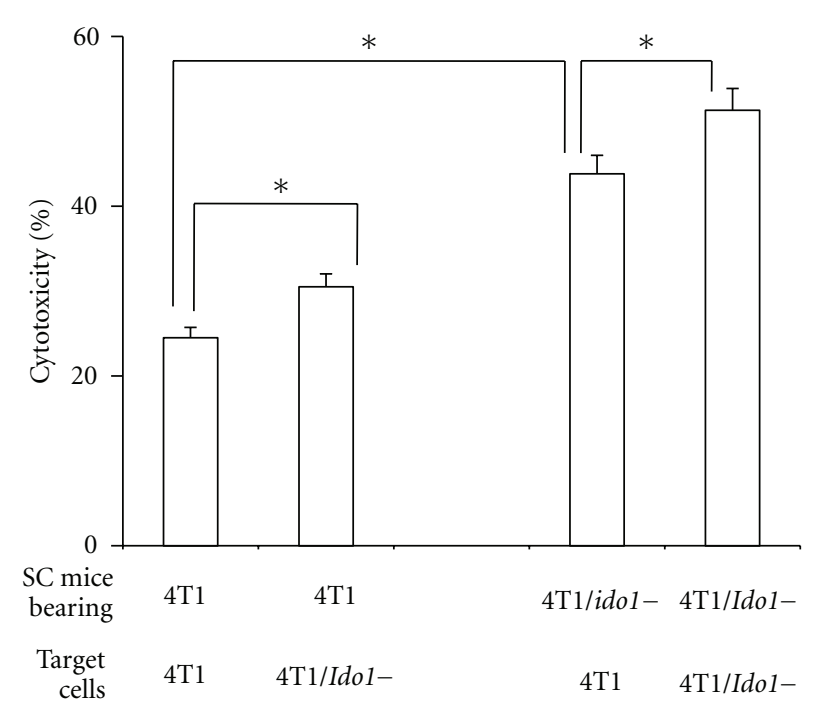

(c)

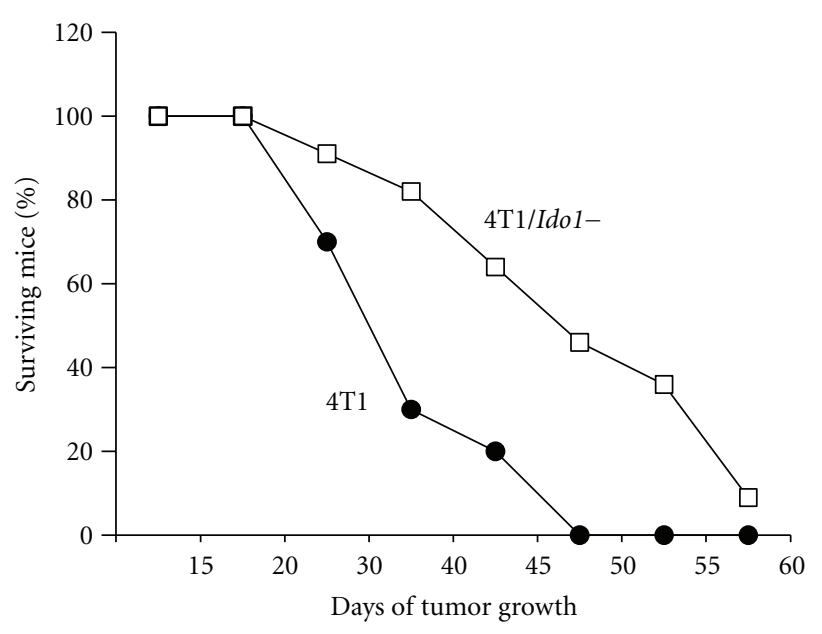

(b)

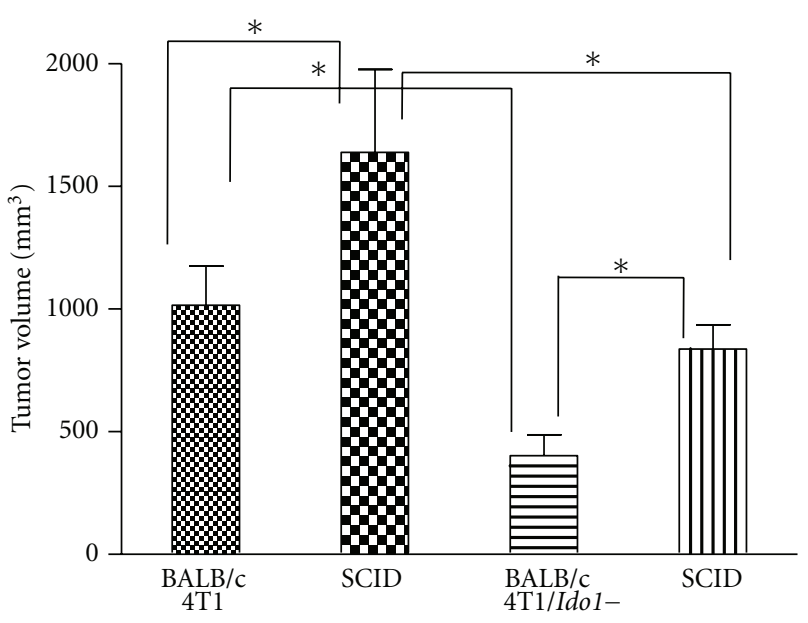

(d)

FIGURE 2: Effect of Ido1 expression on tumor growth and spontaneous metastasis formation. (a) BALB/c mice were inoculated s.c. with $1 \times 10^{5}$ cells/mouse of $4 \mathrm{~T} 1 /$ vector or $4 \mathrm{~T} 1 / \mathrm{Ido1}$ - tumor cells, and tumor growth was monitored. (b) Percentage of surviving mice bearing 4T1/vector and 4T1/Ido1- tumors. (c) Cytotoxic activity of spleen cells from mice bearing 4T1 or 4T1/Ido1- tumors against 4T1 and 4T1/Ido1 - tumor cells. Spleen cells from mice bearing 4T1/vector or 4T1/Ido1- tumors were cultured with irradiated 4T1/vector tumor cells and $300 \mathrm{IU} / \mathrm{mL}$ of IL-2 for 5-8 days. The cytotoxic activity of the spleen cells was tested against ${ }^{51} \mathrm{Cr}-\mathrm{labeled} 4 \mathrm{~T} 1$ or $4 \mathrm{~T} 1 / \mathrm{Ido} 1-\mathrm{cells}$ at the E: T ratio $100: 1$. (d) Growth of 4T1 and 4T1/Ido1- tumors in immunocompetent BALB/c and immunodeficient SCID-beige mice.

sus $\mathrm{S}$ versus $\mathrm{G} 2 / \mathrm{M}$ ) and makes it possible to detect apoptotic cells with fractional DNA content.

Figure 3 represents the results of the experiments in which double staining was applied. Bivariate distribution (contour map) of DNA content and BrdU incorporation in 4T1 and 4T1/Ido1- cells are shown. The 4T1/Ido1- cells growing in control media have significantly $(P<0.05)$ higher percentage of apoptotic cells than $4 \mathrm{~T} 1 / \mathrm{Ido} 1+$ cells. Starvation is a condition that often occurs within the tumors. We analyzed the effect of starvation conditions (low serum in culture medium) on apoptosis induction in 4T1/Ido1+ and 4T1/Ido 1 - cells. Here, the proportion of apoptotic 4T1/ Ido 1 - cells reached $86 \%$, which is approximately 3 times higher than that observed in the $4 \mathrm{~T} 1 / \mathrm{Ido} 1+$ cell population.
The 4T1/Ido1+ cells recover faster after starvation (Figure 3). Cell cycle phase distribution was also different in 4T1/Ido1+ and 4T1/Ido1 - cell populations in control media and under starvation (Figure 3). Control cells showed a significantly higher proportion of cells in the $S$ phase than 4T1/Ido1cells. 4T1/Ido1+ growing in low serum demonstrated a higher proportion of cells in M and G0 phases than 4T1/Ido1cells. We then compared the proliferation of $4 \mathrm{~T} 1 / I d o 1+$ and 4T1/Ido1 - cells as well as NT-5/Ido1- and NT-5/Ido1+ cells in vitro. The results of ${ }^{3} \mathrm{H}$-thymidine incorporation showed a significant reduction in proliferation of Ido1- cells in comparison to Ido1+ cells (Figure 4(a)). Next, the same pairs of $I d o 1+/ I d o 1$ - cells were grown for 3 days and counted as described previously [31]. As shown in Figure 4(b), 
4T1/Ido1+

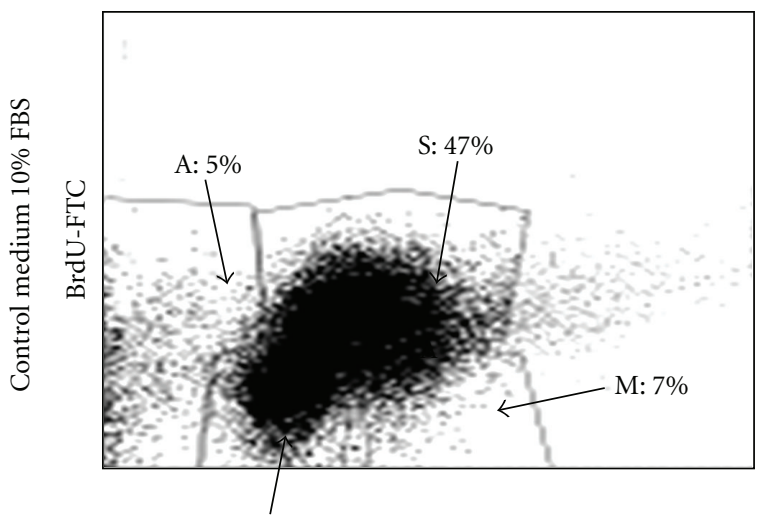

G0: $37 \%$

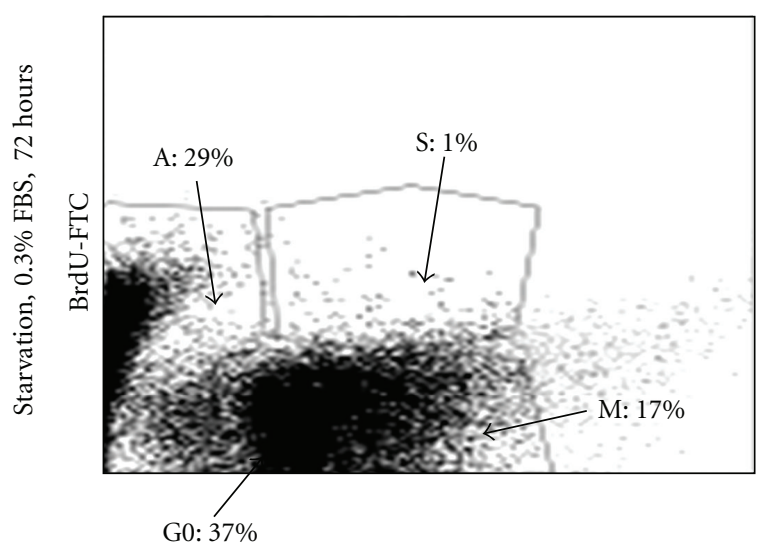

G0: $37 \%$

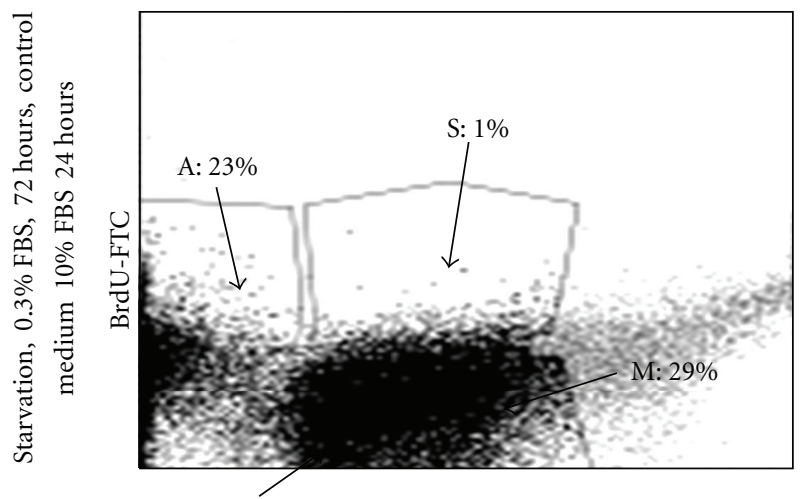

G0: $32 \%$

PI

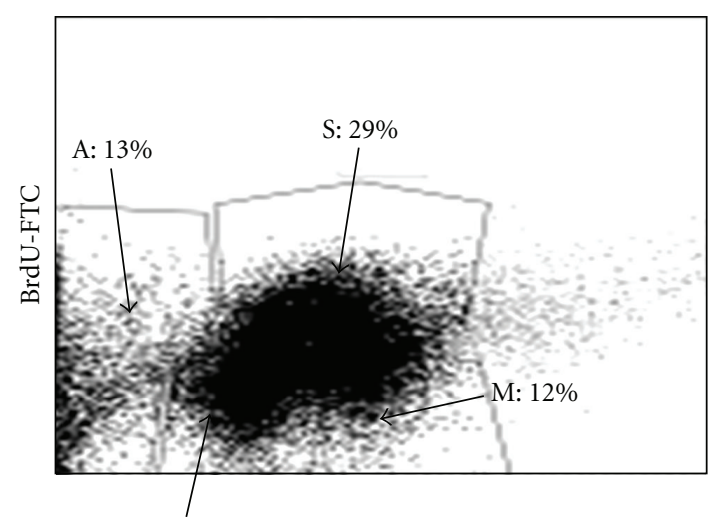

G0: $32 \%$

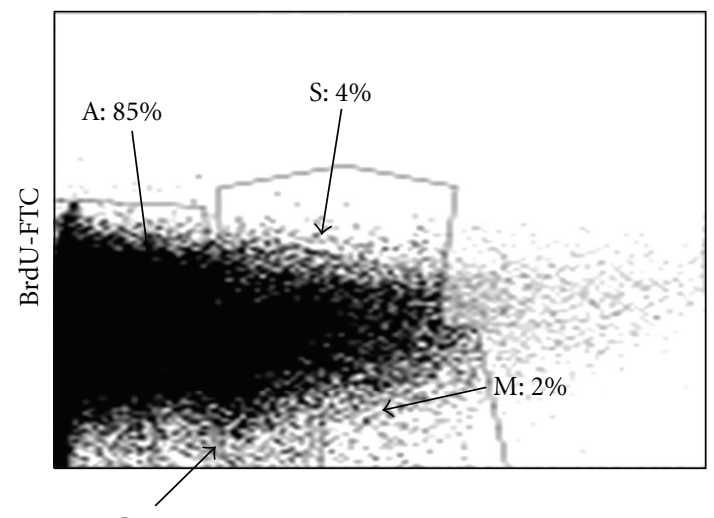

G0: 9\%

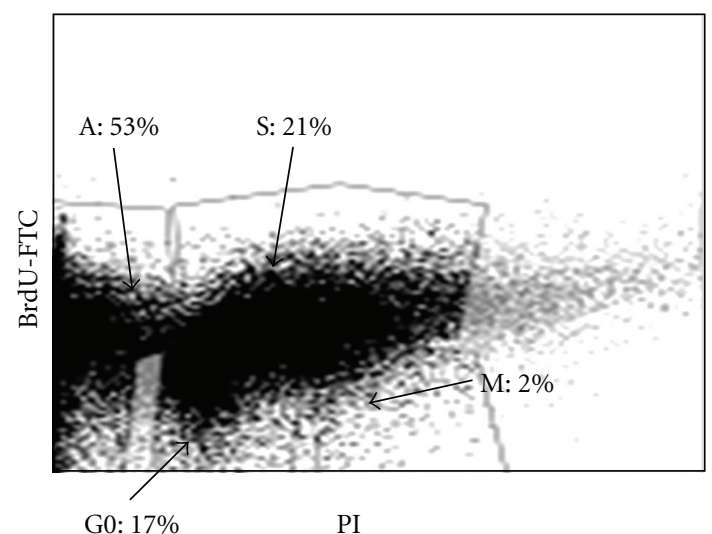

G0: $17 \%$

PI

FIGURe 3: Flow cytometry analysis of apoptosis and cell cycle in Ido1+ and Ido1- cells. 4T1 and 4T1/Ido1- cells were cultured in normal medium ( $10 \%$ FBS), or under starvation condition $(0.3 \%$ FBS $)$ for 3 days followed by a 24 hour recovery in normal medium. Flow cytometry analyses of cells stained with FITC-conjugated antibromodeoxyuridine (BrdU) and propidium iodide (PI) were performed. The data are presented as a percentage of cells in apoptosis (A), G0, S, and M phases.

the inhibition of Ido1 activity in 4T1 cells was associated with an inhibition in $4 \mathrm{~T} 1 / \mathrm{Ido1}$ - cell proliferation, whereas overexpression of Ido1 in NT5/Ido1+ cells stimulated tumor cell proliferation.

3.4. Ido1 and Cell Cycle Gene Expression. To further analyze the differences of the cell cycle regulation in Ido1+ and Ido1- cells, the cell cycle genes expressions were investigated
(Table 2). We used the Mouse Cell Cycle PCR Array from SABiosciences to compare cell cycle gene expression in two pairs of positive and negative Ido1 tumor cells.

Ido1 inhibition in 4T1 tumor cells was associated with significant changes in the expression of 40 cell cycle genes involved in the G1/S transition, S phase, G2/M transition, checkpoints, and $\mathrm{M}$ phase, and the majority of the altered genes were downregulated. Ido1 expression in NT-5/Ido1+ 


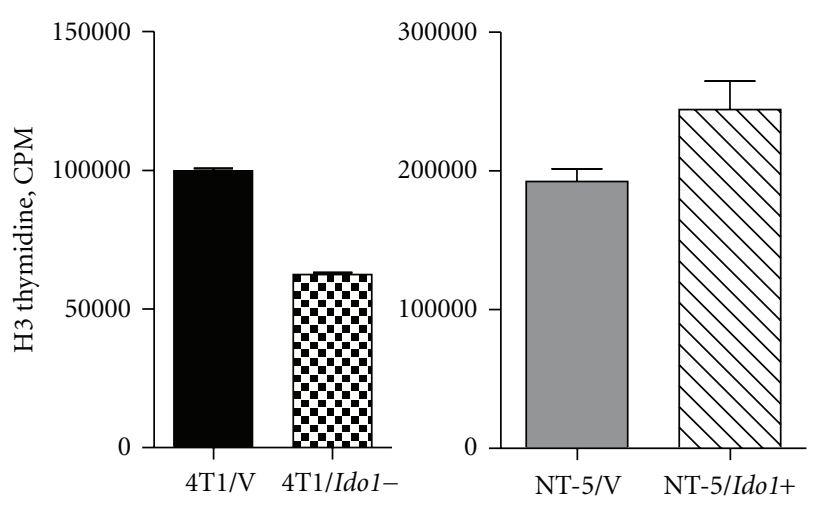

(a)
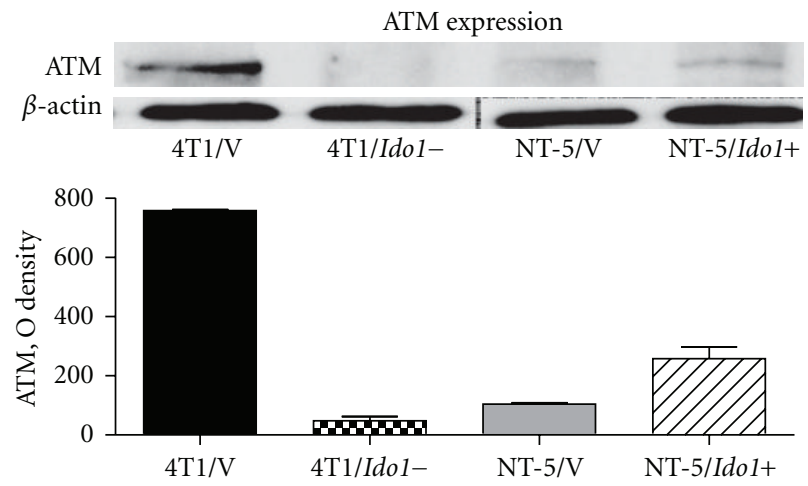

(c)

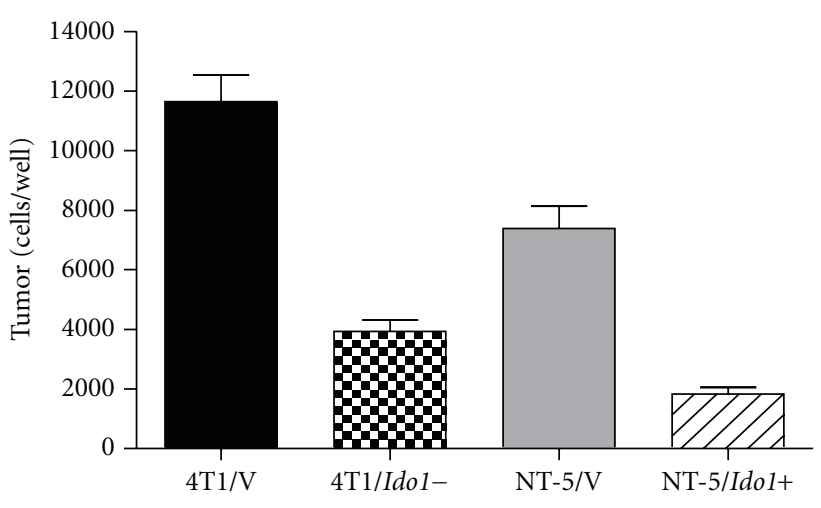

(b)
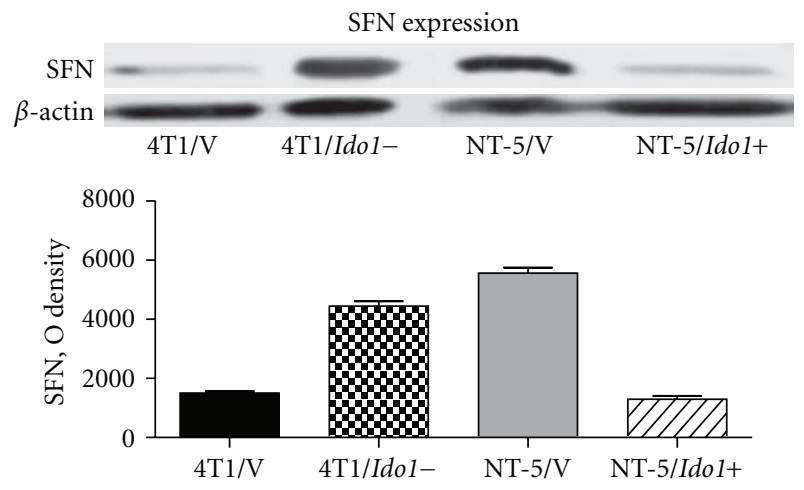

(d)

FIGURE 4: In vitro proliferation and western blot analysis ATM and SFN proteins in Ido1+ and Ido1- breast tumor cells. (a) Analysis of ${ }^{3} \mathrm{H}$ thymidine incorporation and (b) cell counting using Cellomics Array Scan in 4T1/vector, 4T1/Ido1-, NT-5/vector, and NT-5/Ido1+ cells. (c) Western blots analysis of ATM and (d) SFN (14-3-3 sigma protein) expression in 4T1/vector, 4T1/Ido1-, NT-5/vector, and NT-5/Ido1+ cells.

cells correlated with changes in the expression of 14 genes, 13 of which were upregulated (Table 2). The expression of four genes (Trp63(p63), dystonin (Dst), stromal antigen1 (Stag1) and microtubule-actin crosslinking factor (Macf1)) was lower in Ido1 downregulated cells, and higher with IdoI upregulation (Table 2). To verify whether the changes in gene expression are associated with upregulation of IDO1 protein expression in Ido1+ and Ido1 - cells, we performed a western blot analysis of the cell cycle regulators ATM and stratifin (Sfn) $[35,36]$.

Atm (ataxia telangiectasia mutated) is an important cell cycle regulation gene encoding a serine/threonine protein kinase that is recruited and activated by DNA doublestrand breaks. ATM phosphorylates several key proteins that initiate activation of the DNA damage checkpoint, leading to cell cycle arrest, DNA repair, or apoptosis [35, 36]. Atm expression was significantly decreased ( -18.3 -fold) in 4T1/Ido1 - cells and only slightly changed (1.7-fold) in NT5/Ido1+ (Table 2). As demonstrated in Figure 4(c), ATM is expressed in $4 \mathrm{~T} 1 /$ vector $($ Ido1+) cells, and ATM production is dramatically reduced in Ido1- cells.

Stratifin (Sfn), also named 14-3-3 sigma, is a multifunctional protein involved in cell cycle regulation [36]. Downregulation of Ido1 in $4 \mathrm{~T} 1$ cells is associated with upregulation of Sfn gene expression (12 fold); and upregulation of Ido1 in NT5 cells is associated with a decreased level ( -7 fold) of Sfn gene expression (Table 2).

Western blot analysis demonstrated that SFN protein is increased in Ido1- cells, and it is reduced in Ido1+ cells (Figure 4(d)). Thus, the results of the PCR analysis of Atm and $S f n$ gene expression are consistent with the results of the western blot analysis of the ATM and SFN proteins

\section{Discussion}

We first analyzed the impact of Ido1 expression on tumor growth and spontaneous pulmonary metastasis formation and then investigated the IDO1-regulated mechanisms involved in tumorigenesis. One of the key experimental strategies to elucidate the function of a gene in vitro and in vivo is the specific inhibition or upregulation of its expression. Here, we explored both approaches. Ido1+ cells were transected with plasmid expressing shRNA for Idol, and Ido1 - cells were transfected with Ido1 cDNA. These two pairs of $I d o+$ and $I d o-$ clones were evaluated throughout our investigation.

We found that $4 \mathrm{~T} 1 /$ Ido1+ tumors grew faster than 4T1/Ido1- tumors in immunocompetent mice. Growth 
TABLE 2: Ido1 and the cell cycle genes expression in mouse breast tumor cells.

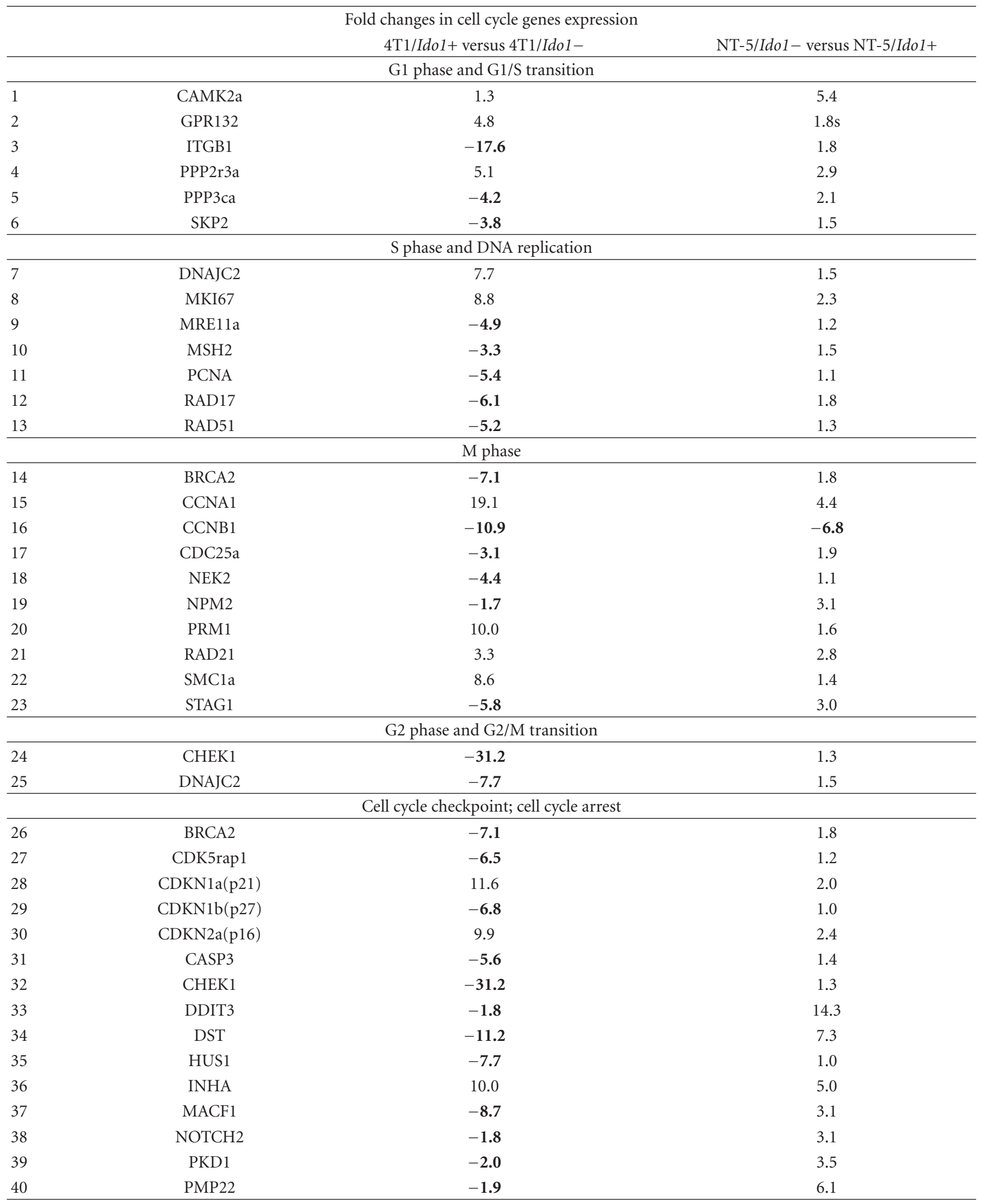


TABle 2: Continued.

\begin{tabular}{lccc}
\hline & & Fold changes in cell cycle genes expression \\
4T1/Ido1+ versus 4T1/Ido1- & NT-5/Ido1-versus NT-5/Ido1+ \\
\hline 41 & SFN & 12.0 & $-\mathbf{7 . 0}$ \\
\hline 42 & & Regulation of the cell cycle & 1.3 \\
43 & ABL1 & $-\mathbf{3 . 4}$ & 1.7 \\
44 & ATM & $-\mathbf{1 8 . 3}$ & 1.3 \\
45 & BRCA1 & $-\mathbf{1 2 . 5}$ & 1.0 \\
46 & CCNC & $-\mathbf{1 1 . 0}$ & 1.5 \\
47 & PBL1 & $-\mathbf{8 . 9}$ & $-\mathbf{1 . 2}$ \\
48 & E2F3 & 3.3 & 6.8 \\
\hline
\end{tabular}

4T1: stable clone with shRNA-negative control vector pGeneClip/Neomycin; 4T1/Ido1-: stable clone with shRNA for IDO.

NT-5: stable clone with control vector pRc/CMV/Neomycin; NT-5/Ido1+: stable clone with cDNA IDO.

* A positive value (normal font) indicates fold of gene upregulation; a negative value (bold) indicates fold of gene downregulation. Genes which were found up/downregulated more than 3-fold at least in the one of the cell line are presented.

inhibition of Ido1 - tumor cells can be attributed to a more efficient immune response. This conclusion is based on the following. (1) Spleen cells from mice bearing 4T1/Ido1tumors generated a higher level of cytotoxic T cells (CTCs). These CTCs were able to destroy 4T1/Ido1 - cells and 4T1/ Ido1+ cells. However, their cytotoxic effects were higher against 4T1/Ido1 - cells, most likely due to a higher sensitivity of these cells to apoptotic signaling. (2) In the absence of major immune mechanisms in SCID/beige mice, the growth of Ido1- tumors was accelerated, suggesting a role for the immune system in Ido1-dependent control of tumor growth. These findings are consistent with previous publications, demonstrating the role of IDO1 in tumor immunosuppression [5-9, 12-14, 37].

Activation of Ido1 by IFN- $\gamma$ links inflammation and cancer immune surveillance $[11,28,35]$, and an increase in IFN- $\gamma$ within the tumor microenvironment also induced IDO1 expression in APCs and DCs that localize to the tumordraining lymph nodes [38]. We found that IFN- $\gamma$ treatment induced Ido1 expression in Ido1+ cells and had no effect on Ido1- cells. Recently, a mouse genetic study revealed a critical role for IDO1 in supporting inflammatory skin carcinogenesis [26]. An analysis of IDO1 dysregulation in cancer showed that JAK/STAT and NF- $\kappa$ B signaling are also essential for IDO1 induction in oncogenically transformed skin epithelial cells [39]. The anti-inflammatory agent, ethyl pyruvate, was found to be able to block Ido1 expression, indicating a link between IDO1 and inflammatory processes [39].

For the first time, we showed that Ido1 regulates tumor metastasis via immunosuppressive mechanisms. Ido1+ tumors develop dramatically higher levels of spontaneous pulmonary metastasis in immunocompetent mice than Ido1- tumors. Levels of lung metastasis in SCID/beige mice (deficient in T cells, B cells, and NK cells) are higher than in immunocompetent mice, thus confirming an immunosuppressive role for IDO1 in spontaneous metastasis formation.

In contrast to our expectation, growth of the Ido1tumors was slower than growth of Ido1+ tumors in immun- odeficient SCID/beige mice, suggesting that some Ido1associated nonimmunological mechanisms may be involved in tumor cell growth regulation. It is conceivable that Ido1cells may have an increased sensitivity to apoptosis signaling or slower cell cycle progression and proliferation than Ido1+ cells. Our in vitro study revealed multiple differences between Ido1- and Ido1+ cell populations suggesting the complexity of IDO1- regulated tumor cell functions. Ido1- cells grow slower than Ido1+ cells. Similarly, the inhibition of IDO expression in rat NMU-induced breast cancer showed the reduced cell proliferation in vitro [40].

Ido1+ cells have small proportions of apoptotic cells in normal media and in starved conditions, and they recover better after starvation. In contrast, 4T1/Ido1 - cells, in which the Idol gene was down-regulated via shRNA transfection, have dramatically increased sensitivity to apoptosis, thus suggesting an important antiapoptotic function of Ido1 in tumor cells. However, molecular pathways involved in Ido1associated apoptosis signaling remain virtually unexplored, offering new areas for investigation.

Cell cycle distributions within Ido1- and Ido1+ tumor cell populations also differ in that Ido1+ cells show a higher proportion of cells in S and M phases than Ido1- cells. Using a comparative RT-PCR analysis of cell cycle regulatory gene expression, we found that downregulation of Ido 1 is associated with decreased expression of multiple genes involved in regulation of G1/S transition, $S$ phase, G2/M transition, checkpoints, and $\mathrm{M}$ phase, whereas upregulation of Ido1 induces expression of these genes. Protein analysis of the products of two genes, stratifin (SFN) and ATM, in $I d o 1+$ and Ido1 - cells show that the up- and downregulation of these genes correlates with the increased/decreased production of their respective proteins. Thus, the roles of Ido1 in breast tumor growth are complex and suggest the involvement of additional nonimmunological mechanisms.

\section{Conclusion}

Our primary finding is that Idol expression has immunological and nonimmunological effects on breast tumor 
growth and spontaneous pulmonary metastasis formation. We demonstrated that IDO1 is involved in the regulation of tumor cell proliferation in vitro and in vivo. Ido1 expression also affects apoptosis in tumor cells. The involvement of IDO1 in cell cycle regulation and tumor cell stress response, in addition to the known role of IDO1 in tumor immunosuppression, make it an attractive target for antitumor therapy.

\section{Authors' Contribution}

V. Levina and Y. Su have equally contributed to this work.

\section{Acknowledgments}

The authors thank Dr. Xiaojun Huang for technical support, and Dr. Brian Nolen for paper editing. This work was supported by the DOD, Award BC051720, Hillman Foundation (E. Gorelik), NIH Grants DK68575, and Award N2929/2907, the Magee Women's Research Institute and Foundation. This work performed using the UPCI Flow Cytometry Facility was supported in part by Award P30CA047904.

\section{References}

[1] D. Hanahan and R. A. Weinberg, "Hallmarks of cancer: the next generation," Cell, vol. 144, no. 5, pp. 646-674, 2011.

[2] R. Kim, M. Emi, and K. Tanabe, "Cancer immunoediting from immune surveillance to immune escape," Immunology, vol. 121, no. 1, pp. 1-14, 2007.

[3] T. Raskovalova, A. Lokshin, X. Huang et al., "Inhibition of cytokine production and cytotoxic activity of human antimelanoma specific CD8+ and CD4+ T lymphocytes by adenosine-protein kinase A type I signaling," Cancer Research, vol. 67, no. 12, pp. 5949-5956, 2007.

[4] Y. Su, E. K. Jackson, and E. Gorelik, "Receptor desensitization and blockade of the suppressive effects of prostaglandin E2and adenosine on the cytotoxic activity of human melanoma-infiltrating T lymphocytes," Cancer Immunology, Immunother$a p y$, vol. 60, no. 1, pp. 111-122, 2011.

[5] A. J. Muller, J. B. DuHadaway, P. S. Donover, E. SutantoWard, and G. C. Prendergast, "Inhibition of indoleamine 2,3dioxygenase, an immunoregulatory target of the cancer suppression gene Bin1, potentiates cancer chemotherapy," Nature Medicine, vol. 11, no. 3, pp. 312-319, 2005.

[6] A. J. Muller, W. P. Malachowski, and G. C. Prendergast, "Indoleamine 2,3-dioxygenase in cancer: targeting pathological immune tolerance with small-molecule inhibitors," Expert Opinion on Therapeutic Targets, vol. 9, no. 4, pp. 831-849, 2005.

[7] D. H. Munn, "Indoleamine 2,3-dioxygenase, tumor-induced tolerance and counter-regulation," Current Opinion in Immunology, vol. 18, no. 2, pp. 220-225, 2006.

[8] D. H. Munn and A. L. Mellor, "Indoleamine 2,3-dioxygenase and tumor-induced tolerance," Journal of Clinical Investigation, vol. 117, no. 5, pp. 1147-1154, 2007.

[9] D. H. Munn and A. L. Mellor, "IDO and tolerance to tumors," Trends in Molecular Medicine, vol. 10, no. 1, pp. 15-18, 2004.

[10] Y. Kudo and C. A. R. Boyd, "Human placental indoleamine 2,3-dioxygenase: cellular localization and characterization of an enzyme preventing fetal rejection," Biochimica et Biophysica Acta, vol. 1500, no. 1, pp. 119-124, 2000.

[11] A. L. Mellor and D. H. Munn, "Tryptophan catabolism and Tcell tolerance: immunosuppression by starvation?" Immunology Today, vol. 20, no. 10, pp. 469-473, 1999.

[12] D. H. Munn, E. Shafizadeh, J. T. Attwood, I. Bondarev, A. Pashine, and A. L. Mellor, "Inhibition of T cell proliferation by macrophage tryptophan catabolism," Journal of Experimental Medicine, vol. 189, no. 9, pp. 1363-1372, 1999.

[13] G. C. Prendergast, "Immune escape as a fundamental trait of cancer: focus on IDO," Oncogene, vol. 27, no. 28, pp. 38893900, 2008.

[14] G. C. Prendergast, R. Metz, and A. J. Muller, "IDO recruits Tregs in melanoma," Cell Cycle, vol. 8, no. 12, pp. 1818-1819, 2009.

[15] R. Yoshida and O. Hayaishi, "Induction of pulmonary indoleamine 2,3-dioxygenase by intraperitoneal injection of bacterial lipopolysaccharide," Proceedings of the National Academy of Sciences of the United States of America, vol. 75, no. 8, pp. 3998-4000, 1978.

[16] R. Yoshida, J. Imanishi, and T. Oku, "Induction of pulmonary indoleamine 2,3-dioxygenase by interferon," Proceedings of the National Academy of Sciences of the United States of America, vol. 78, no. 1, pp. 129-132, 1981.

[17] S. Lob, A. Königsrainer, H. G. Rammensee, G. Opelz, and P. Terness, "Inhibitors of indoleamine-2,3-dioxygenase for cancer therapy: can we see the wood for the trees?" Nature Reviews Cancer, vol. 9, no. 6, pp. 445-452, 2009.

[18] D. H. Munn, M. Zhou, J. T. Attwood et al., "Prevention of allogeneic fetal rejection by tryptophan catabolism," Science, vol. 281, no. 5380, pp. 1191-1193, 1998.

[19] L. Huang, B. Baban, B. A. Johnson, and A. L. Mellor, "Dendritic cells, indoleamine 2,3 dioxygenase and acquired immune privilege," International Reviews of Immunology, vol. 29, no. 2, pp. 133-155, 2010.

[20] P. Ligam, U. Manuelpillai, E. M. Wallace, and D. Walker, "Localisation of indoleamine 2,3-dioxygenase and kynurenine hydroxylase in the human placenta and decidua: implications for role of the kynurenine pathway in pregnancy," Placenta, vol. 26, no. 6, pp. 498-504, 2005.

[21] N. Miwa, S. Hayakawa, S. Miyazaki et al., "IDO expression on decidual and peripheral blood dendritic cells and monocytes/macrophages after treatment with CTLA-4 or interferon- $\gamma$ increase in normal pregnancy but decrease in spontaneous abortion," Molecular Human Reproduction, vol. 11, no. 12, pp. 865-870, 2006.

[22] C. Uyttenhove, L. Pilotte, I. Théate et al., "Evidence for a tumoral immune resistance mechanism based on tryptophan degradation by indoleamine 2,3-dioxygenase," Nature Medicine, vol. 9, no. 10, pp. 1269-1274, 2003.

[23] M. Friberg, R. Jennings, M. Alsarraj et al., "Indoleamine 2,3dioxygenase contributes to tumor cell evasion of T cell-mediated rejection," International Journal of Cancer, vol. 101, no. 2, pp. 151-155, 2002.

[24] M. D. Sharma, B. Baban, P. Chandler et al., "Plasmacytoid dendritic cells from mouse tumor-draining lymph nodes directly activate mature Tregs via indoleamine 2,3-dioxygenase," Journal of Clinical Investigation, vol. 117, no. 9, pp. 25702582, 2007.

[25] A. J. Muller and G. C. Prendergast, "Indoleamine 2,3-dioxygenase in immune suppression and cancer," Current Cancer Drug Targets, vol. 7, no. 1, pp. 31-40, 2007.

[26] A. J. Muller, M. D. Sharma, P. R. Chandler et al., "Chronic inflammation that facilitates tumor progression creates local 
immune suppression by inducing indoleamine 2,3 dioxygenase," Proceedings of the National Academy of Sciences of the United States of America, vol. 105, no. 44, pp. 17073-17078, 2008.

[27] J. Godin-Ethier, L. A. Hanafi, C. A. Piccirillo, and R. Lapointe, "Indoleamine 2,3-dioxygenase expression in human cancers: clinical and immunologic perspectives," Clinical Cancer Research, vol. 17, no. 22, pp. 6985-6991, 2011.

[28] D. H. Munn, A. L. Mellor, M. Rossi, and J. W. Young, "Dendritic cells have the option to express IDO-mediated suppression or not [4]," Blood, vol. 105, no. 6, p. 2618, 2005.

[29] N. Yoshida, K. Ino, Y. Ishida et al., "Overexpression of indoleamine 2,3-dioxygenase in human endometrial carcinoma cells induces rapidtumor growth in a mouse xenograft model," Clinical Cancer Research, vol. 14, no. 22, pp. 72517259, 2008.

[30] O. Takikawa, T. Kuroiwa, F. Yamazaki, and R. Kido, "Mechanism of interferon- $\gamma$ action. Characterization of indoleamine 2,3-dioxygenase in cultured human cells induced by interferon $-\gamma$ and evaluation of the enzyme-mediated tryptophan degradation in its anticellular activity," Journal of Biological Chemistry, vol. 263, no. 4, pp. 2041-2048, 1988.

[31] V. Levina, Y. Su, B. Nolen et al., "Chemotherapeutic drugs and human tumor cells cytokine network," International Journal of Cancer, vol. 123, no. 9, pp. 2031-2040, 2008.

[32] C. J. Aslakson and F. R. Miller, "Selective events in the metastatic process defined by analysis of the sequential dissemination of subpopulations of a mouse mammary tumor," Cancer Research, vol. 52, no. 6, pp. 1399-1405, 1992.

[33] B. A. Pulaski and S. Ostrand-Rosenberg, "Unit 20.2 mouse 4T1 breast tumor model," in Current Protocols in Immunology, chapter 20, John Wiley \& Sons, New York, NY, USA, 2001.

[34] R. T. Reilly, M. B. C. Gottlieb, A. M. Ercolini et al., "HER-2/neu is a tumor rejection target in tolerized HER-2/neu transgenic mice," Cancer Research, vol. 60, no. 13, pp. 3569-3576, 2000.

[35] M. B. Kastan and D. S. Lim, "The many substrates and functions of ATM," Nature Reviews Molecular Cell Biology, vol. 1, no. 3, pp. 179-186, 2000.

[36] C. Laronga, H. Y. Yang, C. Neal, and M. H. Lee, "Association of the cyclin-dependent kinases and 14-3-3 sigma negatively regulates cell cycle progression," Journal of Biological Chemistry, vol. 275, no. 30, pp. 23106-23112, 2000.

[37] X. Zheng, J. Koropatnick, M. Li et al., "Reinstalling antitumor immunity by inhibiting tumor-derived immunosuppressive molecule IDO through RNA interference," Journal of Immunology, vol. 177, no. 8, pp. 5639-5646, 2006.

[38] G. C. Prendergast, R. Metz, and A. J. Muller, "Towards a genetic definition of cancer-associated inflammation: role of the IDO pathway," American Journal of Pathology, vol. 176, no. 5, pp. 2082-2087, 2010.

[39] A. J. Muller, J. B. Duhadaway, D. Jaller, P. Curtis, R. Metz, and G. C. Prendergast, "Immunotherapeutic suppression of indoleamine 2,3-dioxygenase and tumor growth with ethyl pyruvate," Cancer Research, vol. 70, no. 5, pp. 1845-1853, 2010.

[40] M. Hill, V. Pereira, C. Chauveau et al., "Heme oxygenase-1 inhibits rat and human breast cancer cell proliferation: mutual cross inhibition with indoleamine 2,3-dioxygenase," FASEB Journal, vol. 19, no. 14, pp. 1957-1968, 2005. 


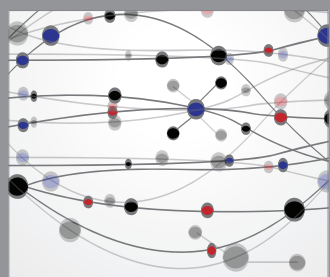

The Scientific World Journal
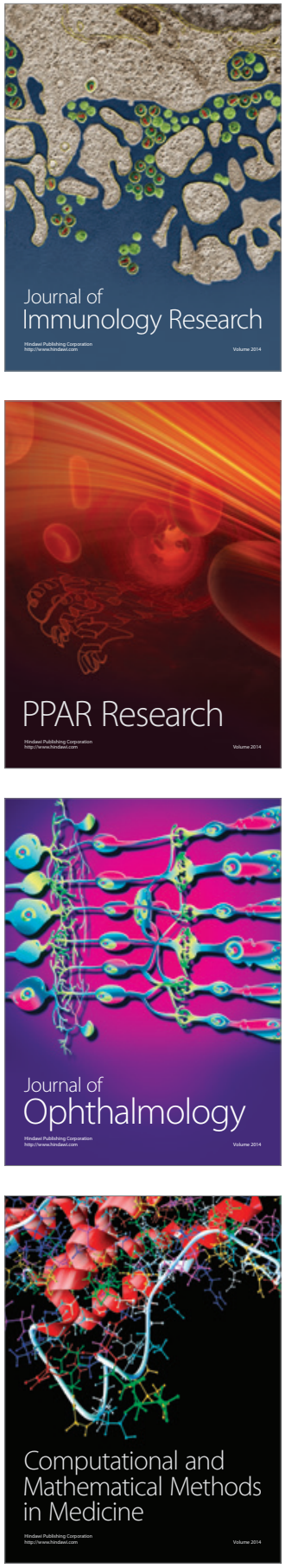

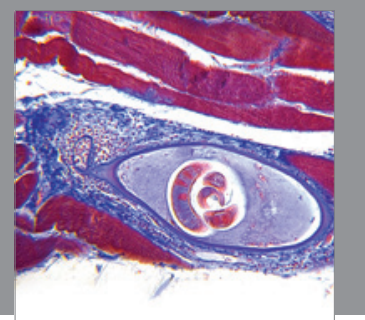

Gastroenterology

Research and Practice
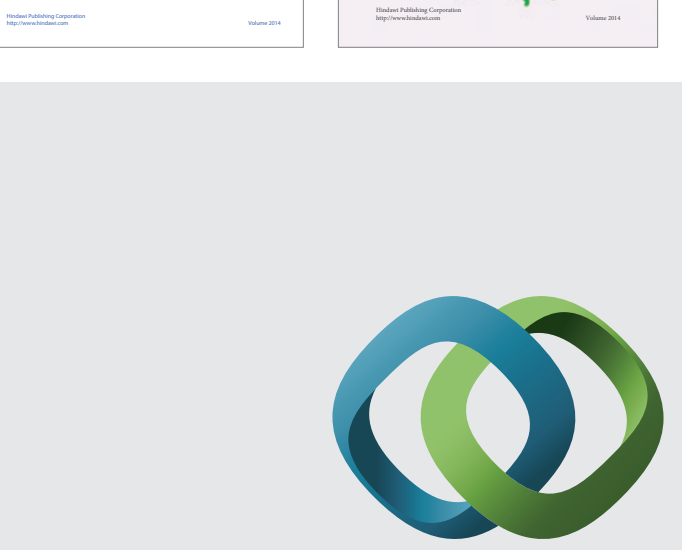

\section{Hindawi}

Submit your manuscripts at

http://www.hindawi.com
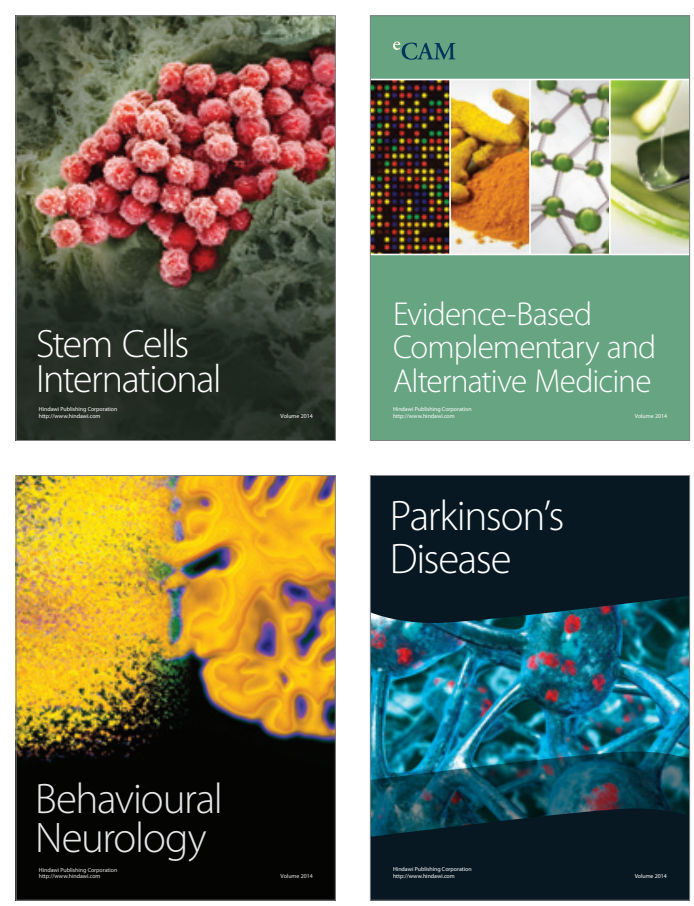

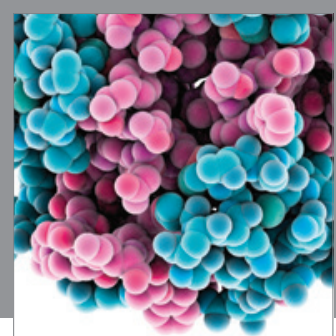

Journal of
Diabetes Research

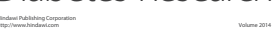

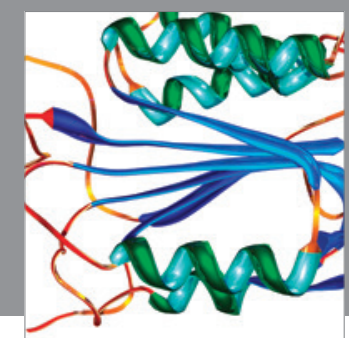

Disease Markers
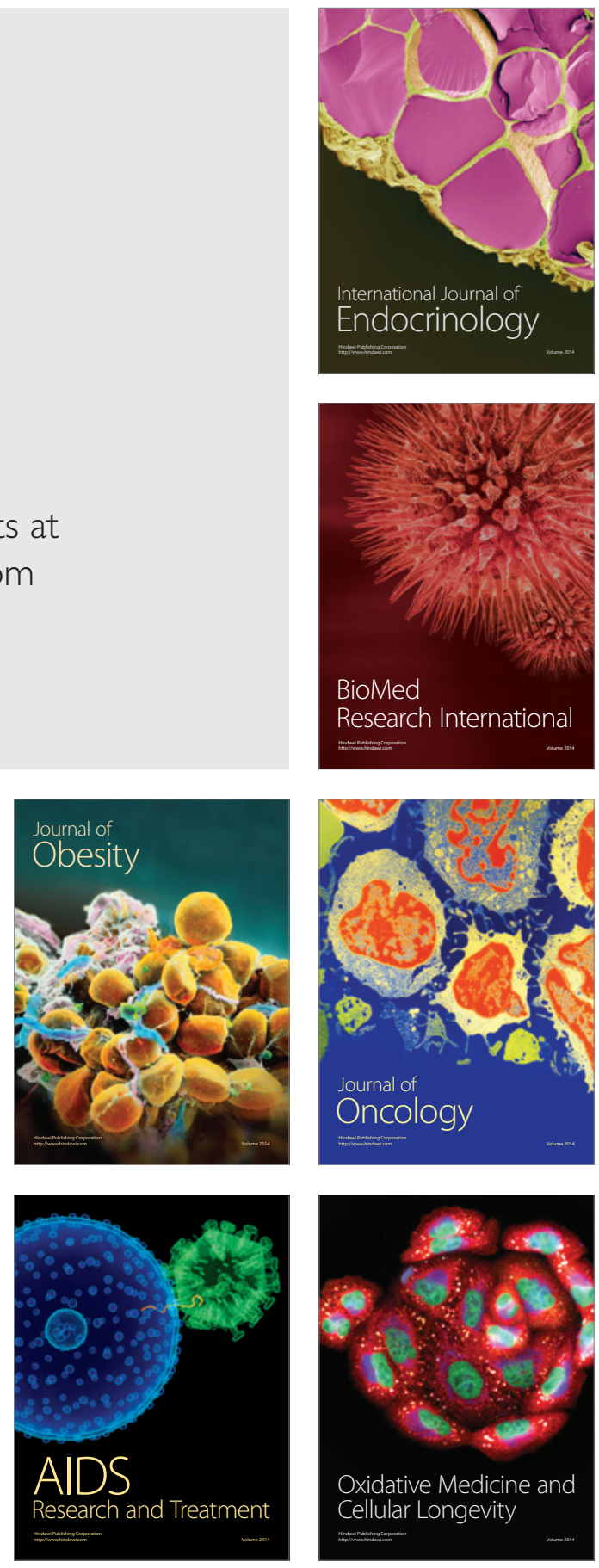